\title{
Current issues in patient adherence and persistence: focus on anticoagulants for the treatment and prevention of thromboembolism
}

This article was published in the following Dove Press journal:

Patient Preference and Adherence

10 March 2010

Number of times this article has been viewed

\author{
Patrick P Kneeland \\ Margaret C Fang \\ The University of California, San \\ Francisco Division of Hospital \\ Medicine, San Francisco, CA, USA
}

\begin{abstract}
Warfarin therapy reduces morbidity and mortality related to thromboembolism. Yet adherence to long-term warfarin therapy remains challenging due to the risks of anticoagulantassociated complications and the burden of monitoring. The aim of this paper is to review determinants of adherence and persistence on long-term anticoagulant therapy for atrial fibrillation and venous thromboembolism. We evaluate what the current literature reveals about the impact of warfarin on quality of life, examine warfarin trial data for patterns of adherence, and summarize known risk factors for warfarin discontinuation. Studies suggest only modest adverse effects of warfarin on quality of life, but highlight the variability of individual lifestyle experiences of patients on warfarin. Interestingly, clinical trials comparing anticoagulant adherence to alternatives (such as aspirin) show that discontinuation rates on warfarin are not consistently higher than in control arms. Observational studies link a number of risk factors to warfarin non-adherence including younger age, male sex, lower stroke risk, poor cognitive function, poverty, and higher educational attainment. In addition to differentiating the relative impact of warfarin-associated complications (such as bleeding) versus the lifestyle burdens of warfarin monitoring on adherence, future investigation should focus on optimizing patient education and enhancing models of physician-patient shared-decision making around anticoagulation.
\end{abstract}

Keywords: anticoagulation, warfarin, adherence, persistence, thromboembolism

\section{Introduction}

Therapy with vitamin $\mathrm{K}$ antagonists such as warfarin is highly effective in reducing morbidity and mortality related to thromboembolism. Numerous trials have demonstrated a clear benefit to treating patients with atrial fibrillation and consensus guidelines now recommend routine anticoagulation in many patient groups with atrial fibrillation. ${ }^{1,2}$ Similarly, some guidelines have advocated for indefinite anticoagulation in certain subsets of patients with venous thromboembolism. ${ }^{3}$ At the same time, recent efforts to enhance patient safety have identified anticoagulants as "high risk" medications, ${ }^{4}$ the proper use of which requires particular scrutiny to maximize clinical safety. ${ }^{5}$ Despite data supporting the use of long-term anticoagulation in a number of patients and increases in physician prescription of appropriate anticoagulant therapy, ${ }^{6,7}$ maintaining patient adherence on long-term warfarin therapy remains a significant challenge due to the risks of anticoagulant-associated bleeding complications and the burdens of frequent monitoring and dose-adjustment. Moreover, provider concerns around patient compliance with anticoagulant regimens likely prevent more widespread adoption of indicated anticoagulation therapy. ${ }^{8}$
Correspondence: Margaret C Fang The University of California, San Francisco Division of Hospital Medicine, 503 Parnassus Ave., Box 013I,

San Francisco, CA 94I43, USA

$\mathrm{Tel}+\mathrm{I}(415)$ 502-7I 00

$\mathrm{Fax}+\mathrm{I}(4 \mid 5)$ 5I4-2094

Email mfang@medicine.ucsf.edu 
The aim of this paper is to review known determinants of patient adherence and persistence on long-term anticoagulant therapy for atrial fibrillation and venous thromboembolism. We evaluate what the current literature reveals about the impact of warfarin use on quality of life, evaluate existing clinical data to identify patterns of patient adherence to warfarin, and summarize what is known about the major risk factors that influence warfarin discontinuation.

\section{Common indications for long-term anticoagulation with warfarin}

Prolonged warfarin therapy is indicated in a number of clinical scenarios other than atrial fibrillation and venous thromboembolism, including for prosthetic heart valves. ${ }^{2}$ However, clinical application of available guidelines for atrial fibrillation and venous thromboembolism remains somewhat unique in that patient preference and values are emphasized as important contributors to the decision to begin and maintain warfarin therapy. ${ }^{1,3}$ Also, physicians demonstrate reluctance to strictly follow guidelines in atrial fibrillation and venous thromboembolism in part due to the perceived barriers to warfarin success in their patients as well as recognition that guidelines around appropriate anticoagulation are difficult to generalize to all patients. ${ }^{8-10}$ In other words, indefinite warfarin use in atrial fibrillation and venous thromboembolism can be viewed by some patients and clinicians as more optional and subject to ongoing comparisons of the risks and benefits of therapy. As such, these clinical scenarios offer a unique opportunity to evaluate the way patient behaviors and preferences impact medication adherence.

\section{Atrial fibrillation}

Atrial fibrillation is the most common clinically significant arrhythmia, affecting around 2.5 million people in the United States - a number bound to rise dramatically as the population ages in coming decades. ${ }^{11,12}$ Atrial fibrillation is an important independent risk factor for stroke, accounting for $15 \%$ of all strokes in the US and up to $36 \%$ of all strokes occurring in patients 80 to 89 years old. ${ }^{13}$ Overall, atrial fibrillation confers a 4- 5-fold increase in ischemic stroke risk, and patients left untreated for atrial fibrillation face a $4.5 \%$ risk per year of suffering a stroke. ${ }^{14,15}$

Numerous well-designed clinical trials demonstrate that oral vitamin $\mathrm{K}$ antagonists such as warfarin sodium substantially reduce the risk of atrial fibrillation-related stroke, such that treating only 32 patients with atrial fibrillation prevents 1 stroke. ${ }^{16-21}$ Moreover, adjusted-dose warfarin is superior to available alternative treatment options, such as anti-platelet therapy with clopidogrel and aspirin. ${ }^{1}$ Based on the cumulative clinical trial data weighing the benefit of stroke prevention versus the risk of adverse effects from warfarin such as bleeding, consensus opinion recommends long-term (lifelong) warfarin treatment (goal INR 2.0-3.0) in patients with additional risk factors for stroke, such as previous stroke, older age, hypertension, diabetes mellitus, and congestive heart failure. ${ }^{1}$

\section{Venous thromboembolism}

Clinically significant venous thromboembolism, particularly deep vein thrombosis (DVT) and pulmonary embolism (PE), represents a considerable public health concern with an annual incidence of about 100 per 100,000 in the general population $^{22-24}$ and with PE causing up to 200,000 deaths annually in the US. ${ }^{25}$ Randomized trials have clearly demonstrated that at least 3 months of warfarin is more effective in preventing recurrent venous thromboembolism than shorter durations. However, certain patient sub-groups, such as those with active cancer or idiopathic venous thromboembolism, have higher rates of recurrent venous thromboembolism and thus may benefit from life-long anticoagulation. ${ }^{26,27}$ At the same time, the benefits of reducing venous thromboembolism recurrence risk must be balanced with an increased bleeding risk and may be strongly influenced by patient preference. ${ }^{3}$ Although several promising strategies have been developed to help estimate a person's risk for venous thromboembolism recurrence, there remains no validated risk scheme that can help clinicians risk-stratify patients to appropriate duration of anticoagulation therapy. ${ }^{10,28,29}$

The 8th American College of Chest Physicians Consensus Guidelines currently recommend indefinite anticoagulation in the following patient subgroups: (1) patients with a first unprovoked proximal DVT without risk factors for bleeding and for whom adequate anticoagulant monitoring is achievable, (2) patients with a second unprovoked DVT, (3) patients with concomitant cancer. ${ }^{3}$

\section{Translating evidence-based recommendations into the clinical setting}

Despite evidence supporting long-term anticoagulant therapy in certain patients, multiple factors, including the necessity of frequent international normalized ratio (INR) monitoring and drug-drug and diet interactions make the translation of evidence-based recommendations into "real-life" challenging. ${ }^{1,9}$ Clearly, tight warfarin control within a narrow therapeutic range is an important practical consideration 
since supratherapeutic INRs (especially $>4.0$ ) raise the risk of severe bleeding complications such as intracranial hemorrhage. ${ }^{18,30-32}$ Likewise, warfarin under-dosing puts patients at significant risk for thromboembolism and stroke. ${ }^{33,34}$ Despite the importance of maintaining warfarin in a therapeutic range, nearly one-half of patients with atrial fibrillation who had stroke despite intention-to-treat with warfarin had inadequate anticoagulation (INR $<1.5$ ) and 30\% were not actively taking warfarin at the time of their stroke. ${ }^{15}$ Data suggest that patients maintain a target INR level only about $50 \%$ of the time ${ }^{35}$ and that as many as $22 \%-33 \%$ of patients newly started on warfarin for atrial fibrillation discontinue therapy within the first year of treatment. ${ }^{36-39}$

Clearly, the appropriate translation of evidence-based recommendations to the real world remains a challenge. Because many patients benefit from appropriate lifelong anticoagulation with warfarin, insights into adherence and reasons for discontinuation have critical implications for improving the quality of anticoagulant care.

\section{Impact of long-term warfarin therapy on quality of life}

Warfarin has a narrow therapeutic window, requiring frequent blood tests and dose-adjustments. ${ }^{40}$ Warfarin effects also may vary in response to changes in diet and other medications. The challenges in maintaining warfarin in an appropriate therapeutic-range combined with increased risk of both major and minor bleeding may contribute to difficulties in convincing patients to take chronic warfarin as well as remain compliant with recommended treatment and monitoring. Despite methodologic challenges when attempting to formally quantify quality of life, ${ }^{41}$ studies have generally challenged assumptions that long-term warfarin therapy significantly and negatively impacts patient quality of life. Warfarin appears to have at most a modest impact on quality of life, and studies suggest a wide range of interpatient variability of quality of life experiences on warfarin, supporting the merit of incorporating individual patient preferences into warfarin treatment decisions.

Health-related quality of life can be estimated as a subjective measure of how physical impediments as well as psychological and emotional discomfort impact a person's day-to-day life. A medication's net impact on a patient's quality of life can be thought of as a balance between the potential side effects of a medication, the burden of complying with an appropriate dose of the medication, and the medication's ability to prevent the targeted adverse health outcome. $^{42}$
Qualitative studies and patient interviews have identified several domains that come into play when considering the impact of long-term warfarin therapy on quality of life (Table 1). These include the inconvenience of taking the medication, inconvenience of frequent blood monitoring, perceived efficacy of the medication, perceived safety of the medication, anxiety related to potential and actual side effects of the medication, patient autonomy, the quality of information given to patients by physicians and shared decision making before starting the medication, symptom alleviation (or prevention), and impact of the medication on physical activities. ${ }^{43}$ In qualitative studies, the most commonly cited difficulties for patients on long-term warfarin include the burden of regular clinic visits, dietary and alcohol restrictions, and worrying about side effects and drug-drug interactions. ${ }^{44}$

However, attempts to formally quantify the effects of warfarin on quality of life have found relatively small effects even when compared to medications (such as aspirin) that do not require the monitoring and restrictions of warfarin. This may be related in part to the value patients place on the potential of warfarin to prevent adverse health outcomes (especially debilitating stroke) over the risk of adverse drug effects or inconvenience of the drug regimen. ${ }^{45}$ Physicians, in fact, may tend to over-emphasize the impact of long-term warfarin on quality of life, and many have speculated that mismatched expectations between physician and patient perceptions of risks, benefits, and lifestyle burden of longterm warfarin may have important implications in underprescribing and medication compliance patterns. ${ }^{8,42,44,46}$

Patients demonstrate considerable variability in their quality of life preferences regarding warfarin therapy for stroke prevention. One study interviewed patients with atrial fibrillation to quantify the impact of stroke using a time-tradeoff method and found that $83 \%$ considered a

Table I Factors that may influence quality of life for patients taking warfarin

Inconvenience of taking the medication

Inconvenience of frequent blood monitoring and clinic visits

Perceived efficacy of the medication in preventing adverse outcomes (ie, stroke)

Anxiety related to potential and actual side effects of the medication Anxiety about potential drug-drug interactions

Extent of shared decision making between the physician and patient when starting the medication

Quality of information given to patients by physicians

Impact of the medication on physical activities

Dietary and alcohol restrictions 
major stroke to be equal or worse than death. ${ }^{41}$ However, about $10 \%$ of patients estimated that the same type of stroke would decrease their quality of life by less than $50 \%$. These patients also generally considered stroke prophylaxis with warfarin to have nearly no negative impact on their quality of life overall, and about the same as using aspirin for stroke prevention. However, $16 \%$ of patients estimated their quality of life on warfarin so low that treatment with aspirin alone would actually be preferred in terms of quality-adjusted life expectancy. Acknowledging that indirect measurements of quality of life, such as by using time-tradeoff estimation, are artificial and difficult to apply to actual patient experience, this study indicates that individual patient preference is likely to play a role in ultimate adherence to a given prophylaxis regimen.

Only one major randomized controlled trial has examined in detail the impact of long-term warfarin therapy on quality of life. ${ }^{47}$ This trial randomized patients with non-rheumatic atrial fibrillation to adjusted-dose warfarin versus control. The study followed patients for over two years and regularly assessed quality of life with validated scales measuring overall functioning, well-being, and health perceptions. Of patients taking warfarin in the study, only $11 \%$ of patients agreed that "taking warfarin restricts my life-style," $22 \%$ said "I worry a lot about the side effects of warfarin," and 3\% agreed "I would be more physically active if I did not take warfarin." Overall, no significant differences in global quality-of-life were found between warfarin and non-warfarin treated patients. However, the study noted that bleeding complications resulted in worsened adverse health perceptions and distress.

Studies of elderly patients $(>75$ years) in the United Kingdom used a validated version of the short form (SF)-36 to measure quality of life before and 6 months after starting warfarin therapy for atrial fibrillation and failed to demonstrate a negative quality of life impact from warfarin, regardless of length of warfarin therapy. ${ }^{42,48}$ In another study, structured interviews of 21 older patients (average age 74 years) with atrial fibrillation on warfarin explored patients' experiences within four domains including "impact on daily life" and "patient satisfaction," finding that for the most part, warfarin was well tolerated and did not pose heavy additional burdens or lifestyle changes; in fact, quality of life appeared to be more influenced by the patient's underlying comorbid conditions. ${ }^{44}$ At the same time, the study acknowledged a wide range in the perceived impact of warfarin therapy, where $\sim 25 \%$ of patients stated that adhering to warfarin has at least some negative impact on their daily life. Locadia et al studied quality of life differences among younger patients (average age 60 years) treated with three versus 6 months of warfarin for deep venous thrombosis. ${ }^{49}$ Similar to studies in patients with atrial fibrillation, there was no difference in quality of life between the two groups at 6 months. Even among young (average age 51 years), indigent, minority patients studied at two Bronx anticoagulation clinics, only $19 \%$ of patients on warfarin reported limitations in their daily life. ${ }^{50}$

While available data argue against attributing a significant negative quality of life impact to long-term warfarin therapy, all of the studies have limitations. For one, we do not know whether quality of life would have been more negatively impacted in patients who were not selected to start warfarin; similarly, little is known about quality of life changes in patients who discontinued warfarin. Most studies were of patients who already elected to take warfarin, individuals who may be at baseline more compliant or agreeable to chronic therapy. Greater variability in quality of life may be more likely in unselected patients. ${ }^{46,51}$ Also, for the most part, studies have evaluated older patients and potentially lack generalizability to younger patients who might experience a more pronounced quality of life detriment when forced to limit activities (like sports) to prevent bleeding. ${ }^{47}$ Finally, the impact of experienced side effects (ie, bleeding), even if minor, likely plays a significant role in determining patient's quality of life while taking warfarin and needs a more robust assessment in future quality of life analyses.

Several anticoagulation-specific quality of life measurement tools have been developed in recent years with the goal of better measuring nuances related to long-term anticoagulation therapy effects on quality of life. ${ }^{43,52,53}$ Future studies using these tools, especially given the development of novel therapies that do not require the monitoring and doseadjustment burdens of warfarin, ${ }^{43,53}$ may uncover important details of how quality of life issues interact with patient experiences on long-term anticoagulation.

\section{Adherence to anticoagulation in clinical trial settings}

Randomized clinical trials that randomly assign patients to either warfarin or an alternative agent can help illuminate the risk of non-adherence related to warfarin, independent of potential confounding factors that affect the validity of observational studies. Because patients are randomly assigned to either warfarin or an alternative, risk factors that may be related to adherence should be equally allocated. 
The majority of warfarin trials have been non-blinded, where only patients randomized to warfarin undergo regular INR testing. In these studies, both medication side-effects and the burdens of monitoring may be factors contributing to non-adherence.

The original clinical trials comparing oral anticoagulants to placebo or aspirin did not consistently demonstrate a compliance difference between the two arms. Some trials reported higher rates of discontinuation in patients randomized to oral anticoagulants ${ }^{16,21}$ while others showed no difference. ${ }^{17-19,55}$

The Atrial Fibrillation Clopidogrel Trial with Irbesartan for Prevention of Vascular Events (ACTIVE W) trial randomized patients to oral anticoagulation or clopidogrel plus aspirin. ${ }^{54}$ The cumulative risk of permanent discontinuation was only $7.8 \%$ for oral anticoagulation versus $13.8 \%$ for clopidogrel plus aspirin. In comparison, the Birmingham Atrial Fibrillation Trial of the Aged (BAFTA) study found that elderly patients were more likely to discontinue warfarin than aspirin therapy. ${ }^{20}$ After a mean follow-up period of 2.7 years, $33 \%$ of individuals randomized to warfarin discontinued therapy, compared to $24 \%$ of patients randomized to aspirin. Notably, discontinuation rates were relatively high in both arms and it is possible that the burdens of warfarin monitoring weighed more heavily in elderly patients.

Newer anticoagulants, such as oral direct thrombin inhibitors and Factor Xa inhibitors may become promising alternatives to warfarin and have the advantage of fixed oral dosing without routine INR measurements. The Stroke Prevention using an Oral Thrombin Inhibitor in Atrial Fibrillation (SPORTIF) III trial randomized patients to open-label warfarin versus ximelagatran, a direct thrombin inhibitor. ${ }^{55}$ Although ximelagatran was taken twice daily at fixed doses and did not require routine INR monitoring, $18 \%$ prematurely discontinued ximelagatran while $14 \%$ discontinued warfarin. The double-blinded SPORTIF V trial, where patients randomized to ximelagatran had sham INR testing to mimic on-warfarin treatment, found no significant difference in the proportion of patients who chose to stop therapy $(10.6 \%$ in the warfarin arm versus $10.0 \%$ in the ximelagatran arm).$^{56}$ The recent Randomized Evaluation of Long-Term Anticoagulation Therapy (RE-LY) trial compared the oral direct thrombin inhibitor dabigatran to warfarin and showed $16.6 \%$ discontinued warfarin at 2 years while $21.0 \%$ discontinued fixed dose dabigatran. ${ }^{57}$ In a subsequent randomized trial comparing warfarin to dabigatran for treatment of acute DVT, treatment was stopped in $1.6 \%$ of patients on dabigatran for non-adherence compared to $2.8 \%$ of patients on warfarin, though the study was not designed to evaluate adherence rates. ${ }^{58}$

In summary, discontinuation and non-adherence rates on warfarin are not consistently higher than in control arms of randomized clinical trials, although elderly patients may be more likely to discontinue warfarin than aspirin. Extrapolating these findings to general clinical care must be done cautiously since randomized trials tend to recruit highly motivated participants who may be more compliant than unselected populations. Additionally, randomized trials have frequent monitoring and follow-up related to the study, which may lead to a higher adherence rate than in general clinical care. Data from observational studies are therefore useful to examine risk factors for non-adherence in real-world settings.

\section{Risk factors for poor adherence to warfarin therapy}

Large proportions of patients in whom warfarin therapy is indicated do not take warfarin, particularly for atrial fibrillation. ${ }^{59-61}$ While the reasons for undertreatment are multiple, the failure to initiate warfarin therapy is responsible for a large percentage of underuse. ${ }^{6,9,62-64}$ At the same time, data suggest that even in patients appropriately initiated on warfarin therapy, many struggle to maintain adherence over the long term. ${ }^{38-40,66}$ Although as described above, there are challenges in quantifying the negative impact of warfarin on quality of life, several risk factors for non-adherence to warfarin have been identified, including younger age, male sex, low overall stroke risk, poor cognitive function, poverty, homelessness, and higher educational attainment (Table 2). Continuing to study and uncover contributing risk factors for non-adherence is important due to the correlation of poor adherence to lower proportions of time spent in therapeutic INR ranges ${ }^{65-68}$ as well as to worse morbidity and mortality. ${ }^{69}$

Table 2 Factors associated with poor adherence to warfarin therapy

Younger age

Male sex

Low overall stroke risk

Poor cognitive function

Poverty

Homelessness

Higher educational attainment

Employment

Reluctant receptivity of medical information 
Preliminary data from the Anticoagulation and Risk factors in Atrial Fibrillation (ATRIA) Study suggest that over one in four patients newly started on warfarin therapy for atrial fibrillation discontinue therapy within 1 year. ${ }^{70}$ These results are consistent with data from clinical trials as discussed above showing a $22 \%$ discontinuation in the first year and 33\% during a mean study period of 2.7 years in patients randomized to warfarin versus alternative agents, 37,39 as well as an observational study demonstrating that $26 \%$ of patients older than 79 years newly started on warfarin had stopped therapy within the first year. ${ }^{38}$ Although a high frequency of hemorrhagic events partially explained the significant discontinuation rate in one study, ${ }^{38}$ discontinuation rates were large even in studies without many major bleeding episodes. ${ }^{37,70}$

Despite the higher risk of hemorrhagic complications in elderly patients, studies have found younger age to be a risk factor for poor warfarin adherence. ${ }^{36,71}$ Men and patients with fewer risk factors for stroke also appear to have lower warfarin adherence rates. ${ }^{36,64,71}$

The INR Adherence and Genetics (IN-RANGE) study examined the prevalence and risk factors of inconsistent warfarin use. ${ }^{72,73}$ Using electronic pill bottle caps to monitor patient adherence over 32 weeks, $92 \%$ had at least one missed or extra bottle opening and $36 \%$ missed more than $20 \%$ of the prescribed bottle openings. Analysis of the IN-RANGE data linked poor adherence to several risk factors, including education beyond high school and being actively employed, but also to lower mental health functioning and poor cognitive functioning. ${ }^{74}$

In terms of educational attainment, the IN-RANGE findings are consistent with previous case-control data, ${ }^{71}$ possibly because higher education may correspond to patient confidence in independent decision making or decreased trust in physicians. Fang et al showed that although limited health literacy was associated with deficits in warfarinrelated knowledge, knowledge and literacy levels were not significantly associated with self-reported adherence or INR control. ${ }^{75}$ Active employment has been found to be a risk factor for poor adherence for both anticoagulation as well as other diseases, ${ }^{67,76}$ possibly because employed patients may have greater competing time interests. While employment may be linked to poor adherence, so might extreme poverty, as data from an underserved urban population demonstrate an association with higher self-reported adherence in individuals with an annual income greater than $\$ 10,000 .^{50}$

While race has been implicated as an independent risk factor for adherence of certain medications, such as anti-hypertensive medications, ${ }^{77-79}$ few studies have looked at the impact of race on adherence to warfarin regimens. Case-control data suggest a trend where non-compliant cases were more likely to be non-white. ${ }^{71}$ There is evidence that some warfarin related racial disparities exist, including worse INR testing frequency among African-American and Hispanic patients ${ }^{80}$ and increased likelihood of AfricanAmericans having subtherapeutic INRs ${ }^{81}$ However, none of these studies demonstrated a difference in adherence based on race, and further studies are needed to understand the interaction, if any.

Investigation into psychosocial determinants specific to warfarin adherence has been limited, but evaluation of medically ill patients in general has identified multiple associated factors including depressive symptoms, perceived lack of social support, poor cognitive function, and poor health related quality of life. ${ }^{82-85}$ In a study of patients on warfarin for non-valvular atrial fibrillation, patients with presumed psychosocial risk factors for non-adherence, in particular substance abuse, had increased risk for adverse medical outcomes, though adherence rates were not directly assessed. ${ }^{83}$ Johnston et al found that only $9.7 \%$ of studied Medicaid patients with new atrial fibrillation filled a prescription for warfarin within 30 days of diagnosis. ${ }^{62}$ In this cohort, alcohol and drug abuse, psychiatric disease, homelessness, and lack of caregiver support were inversely related to warfarin use, though the study could not differentiate between patients who were given a prescription and failed to fill it versus those who never received a prescription. Cognitive functioning has inconsistent associations with adherence, but such studies are likely to be confounded by caregiver involvement. ${ }^{84,85}$

In addition to psychosocial determinants of warfarin use, a few studies have investigated attitudinal correlates to warfarin adherence. A study of patients in an academic anticoagulation clinic evaluated self-reported compliance and found that in addition to being homeless, non-married, and having a higher pill-burden, patients' perceptions of barriers to taking warfarin correlated to worse compliance. ${ }^{86}$ Barriers measured in this case included the perception of taking too many pills, the perception that taking warfarin increases worry about bad health outcomes, and the perception that taking warfarin increases bruising and bleeding. Qualitative data also hint at the potential impact of high pill burden as a perceived barrier warfarin adherence. ${ }^{44}$ In another analysis, Cruess et al found trends linking several attitudinal assessment scores with warfarin non-adherence.$^{87}$ Of these, higher "Information Discomfort," specifically a measure of "patient reluctance to hear information about their medical 
conditions and treatments," was independently associated with poor adherence.

In summary, patients often struggle to maintain adherence with warfarin regimens, potentially leading to more difficult INR control and increasing the risk for adverse health outcomes. ${ }^{72}$ Multiple risk factors seem to predispose patients to inconsistent warfarin use. Among demographic factors, younger age and male sex confer worse compliance, while elderly patients may be among the most adherent groups. In terms of medical comorbidities, a lower risk of stroke confers worse adherence as does poor cognitive functioning. Indirect data suggest that multiple comorbidities and the associated high pill burden may enhance perceived barriers to warfarin adherence among patients. Hemorrhagic events on warfarin surely influence future drug persistence, but questions about the exact relationship of non-adherence to bleeding and the relative weight of minor versus major bleeding events needs further evaluation. Those with higher educational attainment are less likely to demonstrate warfarin adherence as are those currently employed, though the reasons for this are not clear. Homelessness, poverty, and lack of social support are associated with lower adherence. Finally, attitudinal factors including the perception of barriers to compliance and reluctant receptivity of information related to medical conditions may play an important role in determining adherence.

Ultimately, the determinants of warfarin adherence in an individual patient probably exist as a complex matrix of interacting factors. Awareness of these factors and development of strategies to overcome their influence represent potentially important ways to improve not just initiation of warfarin therapy, but also the persistence of that therapy.

\section{Conclusion and future investigations}

Anticoagulant use will likely increase as the national and worldwide population ages in coming decades. As more patients are initiated on warfarin therapy and novel anticoagulant agents are developed, further studies are needed to elucidate the complex interaction of various factors contributing to patient adherence and persistence on anticoagulation. It remains unclear whether monitoring burdens significantly affect subsequent persistence on therapy independent of the associated activity limitations and bleeding complications of warfarin. Measuring the relative impact of warfarin therapy on quality of life is challenging. Newer classes of oral anticoagulants including direct thrombin inhibitors and factor $\mathrm{Xa}$ inhibitors offer the promise of predictable pharmacokinetics and more specific factor targeting that will limit the need for monitoring and may have quality of life advantages over warfarin. ${ }^{88}$ Interestingly, a recent randomized trial comparing oral warfarin to the oral direct thrombin inhibitor dabigatran demonstrated that dabigatran was as good as warfarin at 6 months in preventing recurrent venous thromboemolism, and shared a similar safety profile, but did not require laboratory monitoring. ${ }^{58}$ The study did not directly address quality of life differences. As these new drugs continue evaluation and development, quality of life measurement tools that are specific to anticoagulant therapy will be important when comparing the efficacy of these agents with warfarin. ${ }^{43}$

Clinicians likely influence persistence as well, as patients are more likely to remain on anticoagulation if they have multiple thromboembolic risk factors. Although major bleeding events on anticoagulation are relatively uncommon, minor bleeds may significantly affect both clinician and patient perceptions of the risk of therapy, and thus, subsequent persistence.

Strict adherence to anticoagulant regimens is important to maximize the time spent in a therapeutic anticoagulation intensity. In certain patient populations, such as those who have impaired cognition, interventions such as monthly medication organizers, ${ }^{89}$ interactive voice response systems, ${ }^{90}$ compliance-linked financial incentives, ${ }^{91}$ and at-home warfarin self-management programs, ${ }^{92,93}$ have shown promise in improving adherence.

Attempts to enhance adherence and persistence in individual patients must prioritize patient preference and tailor treatment options appropriately. Evidence highlights a dramatic interpatient variability around perceptions and preferences for antithrombotic prophylaxis, ${ }^{41}$ as well as the problematic nature of physician assumptions about patient preferences. ${ }^{45}$ While patient knowledge about warfarin therapy seems a logical target for shaping patient perceptions of warfarin, anticoagulation education and health literacy alone have not proven to independently predict adherence. ${ }^{75}$ Further exploration of the type and best delivery mode for that information will help shape education strategies in the future. ${ }^{94,95}$ Furthermore, it must be understood that in addition to overt preferences, more subtle patient attitudes - such as perceived adherence barriers ${ }^{86}$ and lack of receptivity to medical information $^{87}$ - may need to be addressed for successful adherence. As such, future investigation should focus on enhancing models of patient-physician shared decision making around anticoagulation. ${ }^{46}$ 


\section{Disclosures}

The authors declare no conflicts of interest.

\section{References}

1. Singer DE, Albers GW, Dalen JE, et al. Antithrombotic therapy in atrial fibrillation: American College of Chest Physicians EvidenceBased Clinical Practice Guidelines (8th Edition). Chest. 2008; 133(6 Suppl):546S-592S.

2. Salem DN, O'Gara PT, Madias C, Pauker SG. American College of Chest Physicians. Valvular and structural heart disease: American College of Chest Physicians Evidence-Based Clinical Practice Guidelines (8th Edition). Chest. 2008;133(6 Suppl):593S-629S.

3. Kearon C, Kahn SR, Agnelli G, et al. Antithrombotic therapy for venous thromboembolic disease: American College of Chest Physicians Evidence-Based Clinical Practice Guidelines (8th Edition). Chest. 2008;133(6 Suppl):454S-545S.

4. Fanikos J, Stapinski C, Koo S, Kucher N, Tsilimingras K, Goldhaber SZ. Medication errors associated with anticoagulant therapy in the hospital. Am J Cardiol. 2004;94(4):532-535.

5. The 5 million lives campaign. http://www.ihi.org/IHI/Programs/ Campaign/. Updated 2009. Accessed December 1, 2009.

6. Stafford RS, Singer DE. National patterns of warfarin use in atrial fibrillation. Arch Intern Med. 1996;156(22):2537-2541.

7. Go AS, Hylek EM, Borowsky LH, Phillips KA, Selby JV, Singer DE. Warfarin use among ambulatory patients with nonvalvular atrial fibrillation: the anticoagulation and risk factors in atrial fibrillation (ATRIA) study. Ann Intern Med. 1999;131(12):927-934.

8. Kutner M, Nixon G, Silverstone F. Physicians' attitudes toward oral anticoagulants and antiplatelet agents for stroke prevention in elderly patients with atrial fibrillation. Arch Intern Med. 1991;151(10):1950-1953.

9. Ezekowitz MD, Falk RH. The increasing need for anticoagulant therapy to prevent stroke in patients with atrial fibrillation. Mayo Clin Proc. 2004;79(7):904-913.

10. Minichiello T, Fogarty PF. Diagnosis and management of venous thromboembolism. Med Clin North Am. 2008;92(2):443-65, x.

11. Go AS, Hylek EM, Phillips KA, et al. Prevalence of diagnosed atrial fibrillation in adults: national implications for rhythm management and stroke prevention: the AnTicoagulation and Risk Factors in Atrial Fibrillation (ATRIA) Study. JAMA. 2001;285(18):2370-2375.

12. Feinberg WM, Blackshear JL, Laupacis A, Kronmal R, Hart RG. Prevalence, age distribution, and gender of patients with atrial fibrillation. Analysis and implications. Arch Intern Med. 1995;155(5):469-473.

13. Wolf PA, Singer DE. Preventing stroke in atrial fibrillation. Am Fam Physician. 1997;56(9):2242-2250.

14. Wolf PA, Abbott RD, Kannel WB. Atrial fibrillation: a major contributor to stroke in the elderly. The Framingham Study. Arch Intern Med. 1987;147(9):1561-1564.

15. Risk factors for stroke and efficacy of antithrombotic therapy in atrial fibrillation. Analysis of pooled data from five randomized controlled trials. Arch Intern Med. 1994;154(13):1449-1457.

16. Petersen P, Boysen G, Godtfredsen J, Andersen ED, Andersen B. Placebo-controlled, randomised trial of warfarin and aspirin for prevention of thromboembolic complications in chronic atrial fibrillation. The Copenhagen AFASAK study. Lancet. 1989;1(8631):175-179.

17. Ezekowitz MD, Bridgers SL, James KE, et al. Warfarin in the prevention of stroke associated with nonrheumatic atrial fibrillation. Veterans Affairs Stroke Prevention in Nonrheumatic Atrial Fibrillation Investigators. N Engl J Med. 1992;327(20):1406-1412.

18. Connolly SJ, Laupacis A, Gent M, Roberts RS, Cairns JA, Joyner C. Canadian Atrial Fibrillation Anticoagulation (CAFA) Study. J Am Coll Cardiol. 1991;18(2):349-355.

19. Secondary prevention in non-rheumatic atrial fibrillation after transient ischaemic attack or minor stroke. EAFT (European Atrial Fibrillation Trial) Study Group. Lancet. 1993;342(8882):1255-1262.
20. The effect of low-dose warfarin on the risk of stroke in patients with nonrheumatic atrial fibrillation. The Boston Area Anticoagulation Trial for Atrial Fibrillation Investigators. $N$ Engl J Med. 1990;323(22):1505-1511.

21. Stroke Prevention in Atrial Fibrillation Study. Final results. Circulation. 1991;84(2):527-539.

22. Heit JA, Melton LJ 3rd, Lohse CM, et al. Incidence of venous thromboembolism in hospitalized patients vs community residents. Mayo Clin Proc. 2001;76(11):1102-1110.

23. White RH. The epidemiology of venous thromboembolism. Circulation. 2003;107(23 Suppl 1):I4-I8.

24. Silverstein MD, Heit JA, Mohr DN, Petterson TM, O'Fallon WM, Melton LJ 3rd. Trends in the incidence of deep vein thrombosis and pulmonary embolism: a 25-year population-based study. Arch Intern Med. 1998;158(6):585-593.

25. Horlander KT, Mannino DM, Leeper KV. Pulmonary embolism mortality in the United States, 1979-1998: an analysis using multiple-cause mortality data. Arch Intern Med. 2003;163(14):1711-1717.

26. Levine MN, Hirsh J, Gent M, et al. Optimal duration of oral anticoagulant therapy: a randomized trial comparing four weeks with three months of warfarin in patients with proximal deep vein thrombosis. Thromb Haemost. 1995;74(2):606-611.

27. Schulman S, Rhedin AS, Lindmarker P, et al. A comparison of six weeks with six months of oral anticoagulant therapy after a first episode of venous thromboembolism. Duration of Anticoagulation Trial Study Group. N Engl J Med. 1995;332(25):1661-1665.

28. Prandoni P, Lensing AW, Prins MH, et al. Residual venous thrombosis as a predictive factor of recurrent venous thromboembolism. Ann Intern Med. 2002;137(12):955-960.

29. Grifoni S, Vanni S, Magazzini S, et al. Association of persistent right ventricular dysfunction at hospital discharge after acute pulmonary embolism with recurrent thromboembolic events. Arch Intern Med. 2006;166(19):2151-2156.

30. Bleeding during antithrombotic therapy in patients with atrial fibrillation. The Stroke Prevention in Atrial Fibrillation Investigators. Arch Intern Med. 1996;156(4):409-416.

31. A randomized trial of anticoagulants versus aspirin after cerebral ischemia of presumed arterial origin. The Stroke Prevention in Reversible Ischemia Trial (SPIRIT) Study Group. Ann Neurol. 1997;42(6):857-865.

32. Gorter JW. Major bleeding during anticoagulation after cerebral ischemia: patterns and risk factors. Stroke Prevention In Reversible Ischemia Trial (SPIRIT). European Atrial Fibrillation Trial (EAFT) study groups. Neurology. 1999;53(6):1319-1327.

33. Hylek EM, Go AS, Chang Y, et al. Effect of intensity of oral anticoagulation on stroke severity and mortality in atrial fibrillation. $N$ Engl JMed. 2003;349(11):1019-1026.

34. Kearon C, Ginsberg JS, Kovacs MJ, et al. Comparison of low-intensity warfarin therapy with conventional-intensity warfarin therapy for longterm prevention of recurrent venous thromboembolism. $N$ Engl J Med. 2003;349(7):631-639.

35. Matchar DB, Samsa GP, Cohen SJ, Oddone EZ, Jurgelski AE. Improving the quality of anticoagulation of patients with atrial fibrillation in managed care organizations: results of the managing anticoagulation services trial. Am J Med. 2002;113(1):42-51.

36. Gallagher AM, Rietbrock S, Plumb J, van Staa TP. Initiation and persistence of warfarin or aspirin in patients with chronic atrial fibrillation in general practice: do the appropriate patients receive stroke prophylaxis? J Thromb Haemost. 2008;6(9):1500-1506.

37. Mant J, Hobbs FD, Fletcher K, et al. Warfarin versus aspirin for stroke prevention in an elderly community population with atrial fibrillation (the Birmingham Atrial Fibrillation Treatment of the Aged Study, BAFTA): a randomised controlled trial. Lancet. 2007;370(9586):493-503.

38. Hylek EM, Evans-Molina C, Shea C, Henault LE, Regan S. Major hemorrhage and tolerability of warfarin in the first year of therapy among elderly patients with atrial fibrillation. Circulation. 2007;115(21):2689-2696. 
39. De Schryver EL, van Gijn J, Kappelle LJ, Koudstaal PJ, Algra A; Dutch TIA trial and SPIRIT study groups. Non-adherence to aspirin or oral anticoagulants in secondary prevention after ischaemic stroke. J Neurol. 2005;252(11):1316-1321.

40. Ansell J, Hirsh J, Hylek E, et al. Pharmacology and management of the vitamin K antagonists: American College of Chest Physicians Evidence-Based Clinical Practice Guidelines (8th Edition). Chest. 2008; 133(6 Suppl):160S-198S.

41. Gage BF, Cardinalli AB, Owens DK. The effect of stroke and stroke prophylaxis with aspirin or warfarin on quality of life. Arch Intern Med. 1996;156(16):1829-1836.

42. Das AK, Ahmed A, Corrado OJ, West RM. Quality of life of elderly people on warfarin for atrial fibrillation. Age Ageing. 2009;38: 751-754.

43. Prins MH, Marrel A, Carita P, et al. Multinational development of a questionnaire assessing patient satisfaction with anticoagulant treatment: the 'Perception of Anticoagulant Treatment Questionnaire' (PACT-Q). Health Qual Life Outcomes. 2009;7:9.

44. Dantas GC, Thompson BV, Manson JA, Tracy CS, Upshur RE. Patients' perspectives on taking warfarin: qualitative study in family practice. BMC Fam Pract. 2004;5:15.

45. Devereaux PJ, Anderson DR, Gardner MJ, et al. Differences between perspectives of physicians and patients on anticoagulation in patients with atrial fibrillation: observational study. BMJ. 2001;323(7323): 1218-1222.

46. Protheroe J, Fahey T, Montgomery AA, Peters TJ. The impact of patients' preferences on the treatment of atrial fibrillation: observational study of patient based decision analysis. $B M J .2000 ; 320(7246)$ : 1380-1384.

47. Lancaster TR, Singer DE, Sheehan MA, et al. The impact of long-term warfarin therapy on quality of life. Evidence from a randomized trial. Boston Area Anticoagulation Trial for Atrial Fibrillation Investigators. Arch Intern Med. 1991;151(10):1944-1949.

48. Das AK, Willcoxson PD, Corrado OJ, West RM. The impact of long-term warfarin on the quality of life of elderly people with atrial fibrillation. Age Ageing. 2007;36(1):95-97.

49. Locadia M, Sprangers MA, de Haes HC, Buller HR, Prins MH. Quality of life and the duration of treatment with vitamin K antagonists in patients with deep venous thrombosis. Thromb Haemost. 2003;90(1):101-107.

50. Davis NJ, Billett HH, Cohen HW, Arnsten JH. Impact of adherence, knowledge, and quality of life on anticoagulation control. Ann Pharmacother. 2005;39(4):632-636.

51. Sweeney KG, Gray DP, Steele R, Evans P. Use of warfarin in nonrheumatic atrial fibrillation: a commentary from general practice. $\mathrm{Br} J$ Gen Pract. 1995;45(392):153-158.

52. Hedner E, Carlsson J, Kulich KR, Stigendal L, Ingelgard A, Wiklund I. An instrument for measuring health-related quality of life in patients with Deep Venous Thrombosis (DVT): development and validation of Deep Venous Thrombosis Quality of Life (DVTQOL) questionnaire. Health Qual Life Outcomes. 2004;2:30.

53. Samsa G, Matchar DB, Dolor RJ, et al. A new instrument for measuring anticoagulation-related quality of life: development and preliminary validation. Health Qual Life Outcomes. 2004;2:22.

54. ACTIVE Writing Group of the ACTIVE Investigators, Connolly S, Pogue J, et al. Clopidogrel plus aspirin versus oral anticoagulation for atrial fibrillation in the Atrial fibrillation Clopidogrel Trial with Irbesartan for prevention of Vascular Events (ACTIVE W): a randomised controlled trial. Lancet. 2006;367(9526):1903-1912.

55. Olsson SB; Executive Steering Committee of the SPORTIF III Investigators. Stroke prevention with the oral direct thrombin inhibitor ximelagatran compared with warfarin in patients with non-valvular atrial fibrillation (SPORTIF III): randomised controlled trial. Lancet. 2003;362(9397):1691-1698.

56. Albers GW, Diener HC, Frison L, et al. Ximelagatran vs warfarin for stroke prevention in patients with nonvalvular atrial fibrillation: a randomized trial. JAMA. 2005;293(6):690-698.
57. Connolly SJ, Ezekowitz MD, Yusuf S, et al. Dabigatran versus warfarin in patients with atrial fibrillation. $N$ Engl $J$ Med. 2009;361(12): $1139-1151$.

58. Schulman S, Kearon C, Kakkar AK, et al. Dabigatran versus warfarin in the treatment of acute venous thromboembolism. $N$ Engl $J$ Med. 2009;361(24):2342-2352.

59. Fang MC, Stafford RS, Ruskin JN, Singer DE. National trends in antiarrhythmic and antithrombotic medication use in atrial fibrillation. Arch Intern Med. 2004;164(1):55-60.

60. Gage BF, Boechler M, Doggette AL, et al. Adverse outcomes and predictors of underuse of antithrombotic therapy in medicare beneficiaries with chronic atrial fibrillation. Stroke. 2000;31(4):822-827.

61. Walker AM, Bennett D. Epidemiology and outcomes in patients with atrial fibrillation in the United States. Heart Rhythm. 2008;5(10): 1365-1372.

62. Johnston JA, Cluxton RJ Jr, Heaton PC, Guo JJ, Moomaw CJ, Eckman MH. Predictors of warfarin use among Ohio medicaid patients with new-onset nonvalvular atrial fibrillation. Arch Intern Med. 2003;163(14):1705-1710

63. Bungard TJ, Ghali WA, Teo KK, McAlister FA, Tsuyuki RT. Why do patients with atrial fibrillation not receive warfarin? Arch Intern Med. 2000;160(1):41-46.

64. Go AS, Hylek EM, Borowsky LH, Phillips KA, Selby JV, Singer DE. Warfarin use among ambulatory patients with nonvalvular atrial fibrillation: the anticoagulation and risk factors in atrial fibrillation (ATRIA) study. Ann Intern Med. 1999;131(12):927-934.

65. Cavallari LH, Aston JL, Momary KM, Shapiro NL, Patel SR, Nutescu EA. Predictors of unstable anticoagulation in African Americans. J Thromb Thrombolysis. 2009;27(4):430-437.

66. Waterman AD, Milligan PE, Bayer L, Banet GA, Gatchel SK, Gage BF. Effect of warfarin nonadherence on control of the International Normalized Ratio. Am J Health Syst Pharm. 2004;61(12):1258-1264.

67. Palareti G, Legnani C, Guazzaloca G, et al. Risks factors for highly unstable response to oral anticoagulation: a case-control study. Br J Haematol. 2005;129(1):72-78.

68. Laporte S, Quenet S, Buchmuller-Cordier A, et al. Compliance and stability of INR of two oral anticoagulants with different half-lives: a randomised trial. Thromb Haemost. 2003;89(3):458-467.

69. White HD, Gruber M, Feyzi J, et al. Comparison of outcomes among patients randomized to warfarin therapy according to anticoagulant control: results from SPORTIF III and V. Arch Intern Med. 2007;167(3):239-245.

70. Fang MC, Go AS, Chang Y, et al. Predictors of warfarin discontinuation in older patients with atrial fibrillation. $\mathrm{J} \mathrm{Am} \mathrm{Coll} \mathrm{Cardiol}$. 2008;51:(A238)

71. Arnsten JH, Gelfand JM, Singer DE. Determinants of compliance with anticoagulation: A case-control study. Am J Med. 1997;103(1): $11-17$.

72. Kimmel SE, Chen Z, Price M, et al. The influence of patient adherence on anticoagulation control with warfarin: results from the International Normalized Ratio Adherence and Genetics (IN-RANGE) Study. Arch Intern Med. 2007;167(3):229-235.

73. Platt $\mathrm{AB}$, Localio AR, Brensinger CM, et al. Risk factors for nonadherence to warfarin: results from the IN-RANGE study. Pharmacoepidemiol Drug Saf. 2008;17(9):853-860.

74. Platt AB, Localio AR, Brensinger CM, et al. Risk factors for nonadherence to warfarin: results from the IN-RANGE study. Pharmacoepidemiol Drug Saf. 2008;17(9):853-860.

75. Fang MC, Machtinger EL, Wang F, Schillinger D. Health literacy and anticoagulation-related outcomes among patients taking warfarin. J Gen Intern Med. 2006;21(8):841-846.

76. Ediger JP, Walker JR, Graff L, et al. Predictors of medication adherence in inflammatory bowel disease. Am J Gastroenterol. 2007;102(7): $1417-1426$.

77. Bosworth HB, Dudley T, Olsen MK, et al. Racial differences in blood pressure control: potential explanatory factors. Am J Med. 2006;119(1):70.e9-70.e15. 
78. Perez-Stable EJ, Salazar R. Issues in achieving compliance with antihypertensive treatment in the Latino population. Clin Cornerstone. 2004;6(3):49-61; discussion 62-64.

79. Raji MA, Kuo YF, Salazar JA, Satish S, Goodwin JS. Ethnic differences in antihypertensive medication use in the elderly. Ann Pharmacother. 2004;38(2):209-214.

80. Birman-Deych E, Radford MJ, Nilasena DS, Gage BF. Use and effectiveness of warfarin in Medicare beneficiaries with atrial fibrillation. Stroke. 2006;37(4):1070-1074.

81. Shen AY, Yao JF, Brar SS, Jorgensen MB, Chen W. Racial/ethnic differences in the risk of intracranial hemorrhage among patients with atrial fibrillation. J Am Coll Cardiol. 2007;50(4):309-315.

82. Wang PS, Bohn RL, Knight E, Glynn RJ, Mogun H, Avorn J. Noncompliance with antihypertensive medications: the impact of depressive symptoms and psychosocial factors. $J$ Gen Intern Med. 2002;17(7):504-511.

83. Schauer DP, Moomaw CJ, Wess M, Webb T, Eckman MH. Psychosocial risk factors for adverse outcomes in patients with nonvalvular atrial fibrillation receiving warfarin. J Gen Intern Med. 2005;20(12): 1114-1119.

84. Nikolaus T, Kruse W, Bach M, Specht-Leible N, Oster P, Schlierf G. Elderly patients' problems with medication. An in-hospital and followup study. Eur J Clin Pharmacol. 1996;49(4):255-259.

85. Schillinger D, Wang F, Rodriguez M, Bindman A, Machtinger EL. The importance of establishing regimen concordance in preventing medication errors in anticoagulant care. J Health Commun. 2006;11(6): 555-567.

86. Orensky IA, Holdford DA. Predictors of noncompliance with warfarin therapy in an outpatient anticoagulation clinic. Pharmacotherapy. 2005;25(12):1801-1808.
87. Cruess DG, Localio AR, Platt AB, et al. Patient Attitudinal and Behavioral Factors Associated with Warfarin Non-adherence at Outpatient Anticoagulation Clinics. Int J Behav Med. 2009.

88. Garcia D, Libby E, Crowther MA. The new oral anticoagulants. Blood. 2010;115(1):15-20.

89. Nochowitz B, Shapiro NL, Nutescu EA, Cavallari LH. Effect of a warfarin adherence aid on anticoagulation control in an inner-city anticoagulation clinic population. Ann Pharmacother. 2009;43(7):1165-1172.

90. Oake N, van Walraven C, Rodger MA, Forster AJ. Effect of an interactive voice response system on oral anticoagulant management. CMAJ. 2009;180(9):927-933.

91. Volpp KG, Loewenstein G, Troxel AB, et al. A test of financial incentives to improve warfarin adherence. BMC Health Serv Res. $2008 ; 8: 272$

92. Fitzmaurice DA, Murray ET, McCahon D, et al. Self management of oral anticoagulation: randomised trial. BMJ. 2005;331(7524):1057.

93. Fitzmaurice DA, Gardiner C, Kitchen S, et al. An evidence-based review and guidelines for patient self-testing and management of oral anticoagulation. Br J Haematol. 2005;131(2):156-165.

94. Mazor KM, Baril J, Dugan E, Spencer F, Burgwinkle P, Gurwitz JH. Patient education about anticoagulant medication: is narrative evidence or statistical evidence more effective? Patient Educ Couns. 2007;69(1-3):145-157.

95. Holbrook A, Labiris R, Goldsmith CH, Ota K, Harb S, Sebaldt RJ. Influence of decision aids on patient preferences for anticoagulant therapy: a randomized trial. CMAJ. 2007;176(11):1583-1587.
Patient Preference and Adherence

\section{Publish your work in this journal}

Patient Preference and Adherence is an international, peer-reviewed, open access journal that focusing on the growing importance of patient preference and adherence throughout the therapeutic continuum. Patient satisfaction, acceptability, quality of life, compliance, persistence and their role in developing new therapeutic modalities and compounds to

\section{Dovepress}

optimize clinical outcomes for existing disease states are major areas of interest. This journal has been accepted for indexing on PubMed Central. The manuscript management system is completely online and includes a very quick and fair peer-review system. Visit http://www.dovepress.com/ testimonials.php to read real quotes from published authors. 